Marine Biology Research

April 2012 ; Volume 8 (5-6) : Pages 475-487

http://dx.doi.org/10.1080/17451000.2011.639778

(c) 2012 Taylor \& Francis

Special Issue: Effects of interactions between fish populations on

ecosystem dynamics in the Norwegian Sea - results of the INFERNO

project

The original publication is available at http://www.tandf.co.uk/journals/

\title{
The rise and fall of the NE Atlantic blue whiting (Micromesistius poutassou)
}

\author{
Mark R. Payne ${ }^{1,2}$, Afra Egan ${ }^{3}$, Sascha M. M. Fässler ${ }^{4}$, Hjálmar Hátún $^{5}$, Jens Christian Holst ${ }^{6}$, \\ Jan Arge Jacobsen ${ }^{5}$, Aril Slotte ${ }^{6} \&$ Harald Loeng ${ }^{6, *}$ \\ ${ }^{1}$ National Institute of Aquatic Resources (DTU-Aqua), Charlottenlund Slot, Charlottenlund, Denmark \\ ${ }^{2}$ Environmental Physics, Institute of Biogeochemistry and Pollutant Dynamics, ETH Zurich, Zurich, Switzerland \\ ${ }^{3}$ Marine Institute, Galway, Ireland \\ ${ }^{4}$ Wageningen Institute for Marine Resources and Ecosystem Studies (IMARES), IJmuiden, The Netherlands \\ ${ }^{5}$ Faroe Marine Research Institute, Noatun, Torshavn, Faroe Islands \\ ${ }^{6}$ Institute of Marine Research, Bergen, Norway \\ *: Corresponding author : Harald Loeng, email address : $\underline{\text { harald.loeng@imr.no }}$
}

\begin{abstract}
:
The Northeast Atlantic blue whiting (Micromesistius poutassou) stock has undergone striking changes in abundance in the last 15 years. The stock increased dramatically in the late 1990s due to a succession of eight unusually strong year classes and dropped again equally dramatically after 2005 when the recruitment collapsed to former levels. The North Atlantic subpolar gyre has previously been shown to have a strong influence on the behaviour of this stock: synchronous changes in the gyre and recruitment suggest a causal linkage and the possibility of forecasting recruitment. A range of mechanisms are reviewed that may explain these observed changes, with two major candidate hypotheses being identified. One hypothesis suggests that the large mackerel (Scomber scombrus) stock in this region may feed on the pre-recruits of blue whiting, with the spatial overlap between blue whiting and mackerel being regulated by the subpolar gyre. Alternatively, variations in the physical environment may have given rise to changes in the amount, type and availability of food for larvae and juveniles, impacting their growth and survival and therefore recruitment. It was not possible to draw firm conclusions about the validity of either of these hypotheses: nevertheless, forecasting recruitment to this stock may be possible in the future if the underlying mechanisms can be resolved.
\end{abstract}

Keywords: Blue whiting, recruitment, recruitment forecasting, sub-polar gyre, physical-biological interactions 
Blue whiting (Micromesistius poutassou Risso, 1827) is a pelagic planktivorous gadoid found throughout the Northeast Atlantic. The species ranges from the Iberian Peninsula and the Mediterranean in the south to the Barents Sea in the north, from the North Sea to the MidAtlantic ridge and even as far as the east coast of North America (Figure 1) (Bainbridge and Cooper, 1973; Baily, 1982 ; Monstad, 2004; Heino et al 2008). However, in spite of the extremely wide geographic range, the species is currently managed as a single stock based around spawning grounds along the continental-shelf edge west of the British Isles (ICES, 2010a).

Both the spawning-stock biomass and recruitment to this stock have varied widely during the period covered by formal stock assessment (1981-2009) (Figure 2). Year classes during the 1980 s and early 1990s were typically around 10 billion individuals. However, unusually large year-classes were produced after 1996 ( $\sim 5$ billion individuals) and particularly in the period 2000-2002 ( $-50-60$ billion individuals), driving an increase in the spawning stock biomass from $\sim 2-3$ million tonnes during the 1980s and early 1990s to a peak of 7 million tonnes in the mid 2000s. The fishery, riding on the back of the strong year-classes, expanded rapidly in the late 1990s and catches peaked at nearly 2.5 million tonnes in 2004, making it one of the largest fisheries in the world at that time. However, in recent times (the 2005 year-class and onwards) the recruitment has declined abruptly to below pre-1995 levels that, together with high catches, has lead to a precipitous recent drop in the spawning stock biomass (ICES, 2010a).

Such dramatic changes pose both severe management challenges and test our scientific understanding. The expansion of the fishery during the late 1990s saw the catch increase by a factor of 500\%: the subsequent recruitment collapse led to a reduction in catch of $75 \%$ between 2004 and 2009, and a recommendation for the closure of the fishery in 2011 (ICES, 2010a). If the mechanisms driving such changes were understood, and if shifts between such high and low recruitment regimes could be predicted in advance, management of this stock could potentially be optimized to avoid such difficulties.

Recent work has hinted at a potential mechanism that may be driving these changes. Oceanographic conditions in the spawning region are dominated by the dynamics of the North Atlantic sub-polar gyre (SPG) (Hátún et al. 2005). A strong SPG results in cold subarctic conditions (Figure 3a), whilst a weak SPG leads to warm saline subtropical conditions around the Rockall Plateau (Figure 3b). Hátún et al. (2009a) showed a link between the spawning distribution of the blue whiting stock and the dynamics of the North Atlantic sub-polar gyre (SPG): distributional changes were seen in observations of larvae, in the spatial distribution of catches and in scientific acoustic surveys covering the spawning region. In a second paper, Hátún et al. (2009b), looked at the biogeography of the Northeast Atlantic more generally, and were able to demonstrate the influence of the SPG across four different trophic levels, from phytoplankton through zooplankton and blue whiting up to pilot whales (Globicephala melas Traill, 1809). This work contributed further to our understanding of blue whiting dynamics, demonstrating that the post-spawning distribution of fish varied in agreement with the SPG. Furthermore, we note here that the rapid increase in recruitment to this stock in the mid-1990s (Figure 2) is coincident with an equally dramatic change in the strength of the SPG (Figure 3c). These results therefore suggest that the SPG has a strong, and possibly determining, influence on the dynamics of the blue whiting population.

Such a linkage can potentially form the basis for recruitment prediction. The dynamics of the SPG are readily observed (Häkkinen and Rhines, 2004), modelled (Hátún et al., 2005) and possibly even forecast (Lohman et al. 2009): if the hypothesised physical-biological linkage can be rigorously demonstrated then a basis for predicting recruitment based on the state of the gyre therefore exists. However, care must also be taken to avoid the common fallacy of making predictions solely on correlations between a physical variable and recruitment: while such statistical correlations may hold in the short term, they tend to break down in the 
medium and longer term (e.g. Meyers, 1998). Elucidating and understanding the underlying mechanisms is therefore a necessary prerequisite for any such forecasting system.

In this work, we review and evaluate the potential mechanisms that could have driven the dramatic rise and fall of recruitment to the NE Atlantic blue whiting stock. The hypothesised linkages with the North Atlantic sub-polar gyre serve as a "red-thread" in this regard, providing a tool to link and generalize diverse physical and biological phenomena. We first examine changes in the physical and biological environment of blue whiting spawning and nursery areas. We then review a set of hypotheses regarding the processes that could impact the recruitment dynamics. Finally, we consider whether recruitment forecasting is currently feasible, given the existing state of knowledge, and draw conclusions about the further elements required to enable such forecasts.

\section{The physical and biological environment}

Blue whiting spawn and spend the larval stage and part of the juvenile stage in the waters west of the British Isles, both along the continental shelf and on and around the Rockall Plateau and Rockall Trough (Bailey, 1982; Hatún et al., 2009a) (Figure 1). The marine climate (temperature, salinity, currents) in this region is highly variable (Holliday 2003) and provides the background against which changes in the recruitment dynamics have occurred. However, the physical processes acting on the different regions within the spawning area (the European Continental Shelf, open-ocean, the Rockall Plateau and the other oceanic banks) differ and the variability that characterizes the sub-regions is therefore also different. Here we examine the dynamics of the physical and biological environments of each region as a way to set the stage for a later examination of any potential coupling with recruitment. The North Atlantic basin is influenced by the increasing Northern Hemisphere temperature trend (Beaugrand et al., 2002), which in turn is related to ongoing climate change (IPCC, 2007). This hemispheric/global trend has a stronger influence on the relatively shallow European Shelf Seas and on the waters near the continental shelf than it has on the much deeper oceanic regions. This type of variability has previously been linked to increases in sea phytoplankton (Edwards et al., 2002) and surface temperature (SST) (Figure 4) and a decline in the copepod Calanus finmarchicus (Gunnerus, 1770) in the North Sea (Planque and Fromentin, 1996).

The importance of the North Atlantic sub-polar gyre in the marine climate of the North Atlantic has recently been recognized (Hatún et al., 2005). This large oceanographic feature is a body of colder, lower-salinity sub-arctic water south of Iceland between the British Isles and Greenland (Figure 3a,b). The interface between the subarctic waters of the gyre and the Atlantic water masses defines the subarctic front and thus the flow path of the North Atlantic Current (NAC) (Wade et al., 1997; Hatún et al., 2005). These dynamics are described by a "sub-polar gyre index" that characterises the extent of the gyre (Häkkinen and Rhines, 2004) (Figure 3c). When subarctic water is present at the southern tip of the Rockall Plateau, a large proportion of the NAC flows into the Rockall Trough and along the eastern side of the Rockall Plateau, embedding the plateau in subarctic water masses (subarctic state - Fig. 3a). This state was primarily observed during the early 1990s, and is associated with low blue whiting recruitment (Figure 2) and a low SPG index (Figure 3c). When, on the other hand, the gyre boundary is located farther west and the NAC mainly flows along the western side of the Rockall Plateau, both the plateau and the region south of Iceland are flooded with warmer and more saline Modified North Atlantic Water (MNAW) (Hansen and Østerhus, 2000) (subtropical state - Fig. 3b). This has largely been the case after 1996, although with shorter term disruptions, and was generally associated with high blue whiting recruitment (at least in the late 1990s and early 2000s) (Figure 2) and a high gyre index (Figure 3c). The splitting of the NAC south of the Rockall Plateau is especially important for the oceanographic environment around Rockall. As the NAC splits around the Rockall Plateau, 
subtle changes in its flow path can cause large and rapid shifts in the marine climate on and around both the Rockall Plateau and in the Iceland Basin. Similarly, a strong influx from the NAC into the Rockall Trough might wash the Rockall Bank with oceanic water, breaking down the local retention system (Dooley, 1984).

These changes in the physical environment are also associated with changes in the biological environment. A weak gyre circulation is characterized by reduced abundances of C. finmarchicus, but increased abundances of the warmer water copepods Pseudocalanus spp, Acartia spp. and Oithona spp. and vice versa when the gyre is strong (Hátún et al. (2009b): these species are among the most important larval prey items for blue whiting (Bailey, 1982). Furthermore, an increasing mean water temperature in the feeding area shifted the southern distribution edge of $C$. finmarchicus, an important prey item for 0- and 1group blue whiting, northwards (ICES 2008).

\section{Processes potentially impacting recruitment}

Many recruitment studies are based on the paradigm that there is a single, clearly identifiable factor responsible for the annual production of marine fish that typically acts during the earliest life-history stages (Houde, 2008; Leggett and Frank, 2008). This "critical period" approach (sensu Hjort, 1914) often focuses on density independent factors affecting recruitment, involving biological responses to both the physical and biological environment. Here we consider the following major processes that can potentially impact the recruitment dynamics: 1) dispersal processes 2) growth rates 3) prey availability and starvation 4) predation 5) the role of stock structure.

\subsection{Dispersal processes}

Dispersal processes are often thought to be an important factor influencing recruitment in fish stocks (Houde 2008). Blue whiting spawn along the shelf edge and banks west of the British Isles from January/February to April/May, with the main spawning occurring during March and April (Skogen et al., 1999). Juveniles are abundant in many areas, but the main nursery area is believed to be the Norwegian Sea (Monstad 2004). During the early lifehistory stages, the larvae are essentially planktonic and therefore the physical and biological environment that they experience is determined by the combination of the spawning location (in time and space) and the currents that carry them. Thus, while dispersal processes do not directly cause mortality, inter-annual changes in dispersal need to be considered in conjunction with processes that can directly cause mortality e.g. starvation, predation.

Several studies using numerical circulation models for simulation of larval drift have been carried out. The possible importance of the variability of the drift pattern for the recruitment of blue whiting has been studied by Svendsen et al. (1996). They showed that large variations in the drift patterns were seen from year to year, but generally much larger amounts of larvae than expected drifted southward from the Porcupine Bank area west of Ireland to the Bay of Biscay. Typically, larvae hatched on the northern side of the Porcupine Bank drift northwards through the Faroe-Shetland Channel, and most of these larvae were located on the shelf. Other work elaborated on this north-south split in drift trajectories in more detail (Bartsch and Coombs, 1997; Skogen et al., 1999), suggesting a separation north of Porcupine Bank at about $53-54^{\circ} \mathrm{N}$. A large degree of interannual variability in these drift patterns was found.

There is, however, an absence of drift studies examining the consequences of the dramatic changes in the sub-polar gyre in the mid-1990s. It is therefore not currently possible to draw conclusions about what the implications (if any) of these potential changes in circulation have been. Furthermore, the relative importance of the drift phase in the population dynamics of this specific stock has not been quantified. Behavioral characteristics of the 
post-larvae, such as shoaling and vertical migration, can also influence the dispersal of individuals. Most importantly, the transition from planktonic to nektonic behavior represents the point at which the juveniles are able to control their own spatial position, and where the significance of oceanic currents starts to diminish. Unfortunately, these processes are currently poorly understood for blue whiting: further behavioral and ontological research is therefore required before a full assessment of the role of dispersion, and its variability, can be undertaken.

\subsection{Growth}

The hypothesis that survival is a direct function of growth has been suggested as a rational theoretical framework for recruitment research (Anderson 1988). In the growth-mortality hypothesis (Ware, 1975; Shepherd \& Cushing, 1980), it is hypothesized that predation decreases with increasing size (Folkvord \& Hunter, 1986; Pepin 1991). Higher growth rates therefore enhance the chance of survival by reducing the duration of the "predation window", i.e. the time the larvae is "small" and an easy target for predators. Conditions that determine growth rates during the larval phase, such as food availability (direct) and increased ambient temperature (indirect) leading to faster growth, will therefore ultimately determine survival. Pepin et al. (1987) demonstrated that this is generally true for vertebrate and invertebrate marine predators. There are unfortunately no known studies that have examined the relationship between growth rates and survival/mortality in blue whiting. Nevertheless, by extension from other species, this hypothesis could be expected to play a significant role in the survival of the early life stages of blue whiting.

Larval growth histories determined from otoliths can provide a useful tool to understand the variability in growth. Recent work on blue whiting (Brophy and King, 2007) has shown that groups that are spatially or temporally distinct after hatching have measurable differences in the larval portion of the otolith. Larvae from the Bay of Biscay were found to grow faster than those from more northerly spawning areas, suggesting that mixing of fish from these areas is limited. Furthermore, fish spawning to the west of Ireland and Scotland do not form a randomly mixing unit: subunits within this aggregation have experienced differences during the larval phase. The factors responsible for the variability that was observed in otolith growth were not tested by this study. It is likely that differences in larval otolith growth rate reflect variations in temperature and food supply along larval drift trajectories, and they may also be influenced by the timing of hatching and by selective mortality during the larval phase.

\subsection{Prey}

Larval survival is influenced by both the quantity and quality of suitable prey items. These factors could be the reason for the apparent higher survival rates when the waters around the Porcupine Bank and the Rockall Bank originate from the south (sub-tropical waters I weak SPG) and contain higher proportions of suitable prey. On the other hand, the water masses coming from the west, when the subpolar gyre is strong, contain significantly different fauna (Hátún el al. 2009b). Unfortunately, the details of the prey preferences of blue whiting larvae and juveniles are poorly understood, and so it is not currently possible to assess whether these changes have an impact or not.

Food limitation could be a significant issue for this stock. The Nordic Seas are typically considered the main nursery and feeding grounds for blue whiting (e.g. Baily 1982; Monstand 2004) and the Norwegian Sea has historically been thought to produce enough zooplankton to feed the large amount of pelagic fish that live there (Skjoldal, 2004). However, the biomass of zooplankton (i.e. mostly Calanus spp.) in the Norwegian Sea and adjacent areas has decreased during the last fifteen years (ICES, 2010b) (Figure 5). In parallel, the combined biomass of pelagic fish (blue whiting, mackerel (Scomber scombrus L., 1758) and Norwegian spring spawning herring (Clupea harengus L., 1758) has 
increased (ICES, 2010a). The question therefore can be posed: is there enough food in the Norwegian Sea to feed more than 20 million tonnes of pelagic fish? Have the pelagic stocks reached a size where they negatively affect their own recruitment through overgrazing of their food resources? It can be postulated that the low plankton abundance would put pressure on young ( 0 and 1 group) blue whiting feeding on small zooplankton in the area. However, how, or whether, these significant changes relate to the survival of blue whiting eggs and larvae is not immediately obvious: at best, such a hypothesis could explain the decrease in recruitment from 2005 onwards (i.e. by starvation of juveniles and/or poor parental condition) but not the post-1996 increase. More detailed studies are therefore needed to quantify these effects and their potential implications for the blue whiting stock.

\subsection{Predation}

Predation is a complex factor in the survival of larvae that is poorly understood (Bailey and Houde, 1989; Fuiman, 1994), both in general and specifically for blue whiting. Both the intensity of predation and the major predators change throughout the life history of a fish e.g. predation by invertebrates generally decreases substantially during the late-larval stage, whereas the predation pressure exerted by fish increases (Fuiman and Gamble, 1989). Predation must also be considered in a spatial context: variations in the overlap between predators and prey can also change survival rates.

Mackerel are a potential major predator on blue whiting eggs, larvae and juveniles. Mackerel are known to prey upon juvenile blue whiting: Olaso et al. (2005) demonstrated a shift in the mackerel diet from over $90 \%$ krill (euphausiids) to over $90 \%$ blue whiting from spring to autumn off northern Spain. Cabral and Murta (2002) also found that blue whiting was the main prey in mackerel stomachs off Portugal. The northeast Atlantic mackerel stock is large and widely distributed and is currently at historic highs with an estimated SSB of around 3 million tonnes (ICES, 2010a). This mackerel stock therefore has the theoretical ability to impact the juvenile blue whiting population.

Importantly, there are indications that the intensity of mackerel predation upon blue whiting is not constant in time. The spawning distribution of blue whiting has been shown to be regulated by the dynamics of the sub-polar gyre (Hátún et al. 2009a) with spawning taking place along the continental shelf-edge when the gyre index is low (sub-arctic state; early 1990s), and around Rockall plateau when the gyre index is high (sub-tropical state; late 1990s). Mackerel egg-surveys, on the other hand, have shown that their spawning distribution tends to be more limited to the continental shelf-edge during the March-April period, while later in April and May the mackerel seem to spread over the entire spawning area of blue whiting (ICES, 2010b). The spatial overlap between the spawning distribution of blue whiting and mackerel might therefore vary in accordance with the sub-polar gyre, with reduced overlap (and therefore predation) in years with good blue whiting recruitment and a high gyre index (Figure 6).

The hypothesis of mackerel predation is therefore consistent with the data currently available. Mackerel may prey upon the juvenile blue whiting, thus affecting blue whiting recruitment negatively, with the intensity of this process being modulated, in the first instance, by the sub-polar gyre. However, many key pieces of this hypothesis are still missing: it is not clear, for example, at which stage the predation takes places (specifically on eggs, larvae, or juveniles, or across all stages?). Further investigation is therefore required to explore this hypothesis. Stomach sampling of mackerel on the blue whiting spawning grounds and downstream of these areas throughout the year would form a logical first step in this direction.

\subsection{Stock structure}

Changes in stock structure can have a considerable influence on the reproductive potential of a stock and can in turn contribute to the recruitment variability (Trippel, 1998; Marshall et 
al., 2003, 2006). It is quite common that first-time spawners spawn later in the season than the repeat spawners (Slotte et al., 2000). Hence, the proportion of recruits among the spawners may have a significant effect on spawning time, thereby indirectly affecting the survival since hatching time is found to be a significant factor influencing recruitment in fish (Fortier and Quinonez-Velazquez, 1998; Lapolla and Buckley, 2005; Nishimura et al., 2007; Husebø et al. 2009). Unfortunately, there is currently insufficient information available to reliability assess changes in spawning date in this stock.

Large changes in the stock structure can be expected, given the large changes observed in recruitment. Such changes would have been especially important at the start of the highrecruitment period (spawning stock dominated by first time spawners) and the end (spawning dominated by repeat spawners). However, the dramatic changes in recruitment contradict the expected effects of changes in stock structure (poorer recruitment in first-timespawner-dominated scenarios). Changes in recruitment therefore appear to have induced changes in the stock structure (rather than vice versa): it would appear that this is, at most, a second order effect.

\section{Potential for Prediction}

The previous section examined a range of candidate mechanisms that may account for the wide range of recruitment levels observed in the blue whiting stock in recent times. Under the assumption that all of these hypotheses are (or could be) understood, there is therefore the (theoretical) potential for making predictions about recruitment to this stock. However, in order to make such a prediction, it is first necessary that we understand the system at hand, and particularly the processes driving it: the break-down of simple recruitment-environment correlations several years after their publication is a well known and well documented phenomenon in the fisheries literature (Myers, 1998). Given the uncertainty in our current state of biological knowledge, we therefore avoid making outright predictions. Instead, we illustrate how such a system might be developed and structured.

When considering any form of prediction, it is useful to have a baseline prediction model against which to compare other models: only in cases where the proposed prediction scheme can be shown to outperform the baseline case should the newer scheme be considered. A common basis for predicting and projecting recruitment to a fish-stock is using a relationship between the spawning stock biomass (SSB) and recruitment (Myers et al. 1994). Such a model has the advantage that it includes mechanistic understanding (SSB can be interpreted as a proxy of stock reproductive potential), and if sufficiently strong, can be propagated many years into the future. However, a relationship between spawning-stock biomass and recruitment in this stock is essentially absent (Figure 7a), with no clear functional form, and a very high degree of scatter about similar biomass levels. We therefore conclude that such an approach is not possible with the time series of data currently available.

An alternative approach is to forecast the recruitment based on the state of the oceanographic system. Previously we have suggested potential mechanistic linkages between the recruitment and the oceanographic conditions: such a forecast would therefore have at least some mechanistic understanding to support it. However, the correlation between the gyre index and the (log) year-class strength is not significant $(p=0.594, r=0.10$, Figure $7 b$ ). Similarly, there is no significant correlation between the (log) recruits per spawner in a cohort and the gyre index $(p=0.173, r=0.27)$. The relationships between the gyre index and either recruitment metric are therefore indistinguishable from random noise, and therefore are not suitable as a basis for forecasting either.

We note the high degree of auto-correlation apparent in the time series of recruitment (Figure 2), and therefore propose a model based around the premise that "recruitment next year will be the same as this year". The correlation between recruitments in successive 
years is highly significant $(p<0.001, r=0.78$, Figure $7 c)$, suggesting strong support for this model. Longer time lags were examined, but were not found to be significant. This suggests a significant potential prediction mechanism one year into the future by simply assuming that the next recruitment will be the same as that in the current year. However, whilst it might be statistically strong, such a model is of little use in predicting when the changes between states occur. Furthermore, in the absence of any real process understanding, the long-term robustness of such a model is unclear. Nevertheless, it provides a useful baseline against which other future potential models should be tested: only in cases where the proposed model can be shown to statistically outperform this simple baseline model should the new model be accepted.

\section{Discussion}

The general inability of the marine science community to understand and predict recruitment to fish stocks stems from the inherent complexity of the process. At the most fundamental level, recruitment variability can be viewed as the outcome resulting from the variable number of offspring (eggs) produced as well as the integrated and variable effects of density-independent and density-dependent processes on all pre-recruit stages. Densitydependent processes include competition for food with conspecifics and/or offspring of other species, predation by other species and the possibility of cannibalism. Included here are also the potential effects of changes in stock structure e.g. proportion of older, repeat spawners in the population, which may affect both egg quality and spawning time, and thereby indirectly affect the recruitment. Density-independent factors include all the physical processes influencing pre-recruits and their prey, hereunder changes in temperature, salinity and dispersion processes.

Two major hypotheses were developed here that may account for the remarkable changes in recruitment to the blue whiting stock (Figure 8). The "food" hypothesis suggests that changes in the "prey" (biological) environment are key, as they influence the amount, type and/or distribution of prey that are available to the pre-recruits. Individual growth is therefore impacted, and in turn gives rise to changes in survival and recruitment via multiple mechanisms: larvae can potentially starve, if there is insufficient prey (c.f. Figure 5) or may experience different predation mortality rates (via the growth-mortality hypothesis).

Atlernatively, the "predation" hypothesis is centred upon the role of mackerel predation upon blue whiting. Changes in the spawning distribution change the distribution of spawning products and thus the overlap of adult mackerel and blue whiting pre-recruits. Changes in the overlap modulate the intensity of predation and thus impact survival rates and recruitment.

Other secondary processes can also be envisaged. For example, changes in the physical environment can also impact the temperatures experienced by the early-life stages, altering the growth characteristics and prey requirements and thus modulating both the probability of starvation and the intensity of predation (again via the growth-mortality hypothesis).

It was not possible to accept or reject any of these major hypotheses directly. Whilst there appears to be good evidence supporting them, it is important to emphasise that these are still only hypothesises, both of which are still lacking key pieces of the puzzle. Even more critically, the underlying assumption of recruitment being controlled by a single, constant process (e.g. Hjort, 1914) is also most probably incorrect - the true underlying mechanisms may actually be a combination of these, or other, processes, whose importance varies on decadal, inter-annual or even intra-annual time scales. Thus, the hypotheses presented here should be considered only as a framework for future research, rather than conclusions in themselves.

The North Atlantic sub-polar gyre is the common thread linking these processes: all proposed mechanisms can ultimately be traced back to the gyre. This is not surprising 
considering its importance: the gyre is the dominant feature controlling the environment in the region where blue whiting spawn and grow up, and impacts both the physical (temperature, salinity) and biological (plankton abundance and type) characteristics of this region (Hatún et al., 2005, 2009b). However, although there is synchronicity between the dramatic changes in the gyre and changes in recruitment, there is no direct correlation between the gyre index and recruitment over the time periods considered here (Figure $7 \mathrm{~b}$ ). This does not mean that the gyre does not have an effect on recruitment: the changes around 1996 and the effects on various levels of the ecosystem together with the mechanisms proposed here all indicate a role. Rather, these results suggest that the relationship is more complex than a simple one-to-one equality indicated by a correlative analysis and that more than one of the multiple pathways proposed in Figure 8 may be at play.

The key to predicting recruitment lies in the understanding of the actual processes regulating recruitment, and how they are potentially influenced by external drivers. We have focused predominately on the density-independent processes here, as they generally tend to be more amenable to scientific investigation. However, density-related effects, such as the effect of high abundances of pelagic fish (including blue whiting) on the abundance of zooplankton in the Norwegian seas, have also been proposed. Many of these processes are, in turn, linked, directly, or indirectly, to the physical environment, which is generally much better understood in terms of observations, modelling and the ability to forecast. If the assumed linkage between the physical environment and recruitment can be demonstrated rigorously, the existing and constantly improving ability to predict the physical environment could be exploited, at least in theory, to generate reliable recruitment predictions. However, a key caveat remains: without a detailed understanding of the link between the two, there is no rational basis for making predictions.

\section{Conclusions}

In this work, we have investigated the recruitment dynamics of blue whiting in the NE Atlantic with a view to understanding the mechanisms driving the dramatic changes observed and to assess whether it is possible to make recruitment forecasts. We have generated and examined a series of mechanistically-based hypothesises that can potentially explain the observed changes. However, whilst there appear to be several strong candidate hypothesises, there is no objective basis to choose between them. We therefore conclude that in the absence of a mechanistic understanding of the system, it is not currently possible to make recruitment forecasts. Resolving the hypotheses developed here, however, may render such forecasts feasible.

\section{Acknowledgements}

This manuscript was produced by the Workshop on Blue Whiting Recruitment (WKBLUR) (ICES 2009), formed under the auspices of the International Council for the Exploration of the Sea (ICES). The authors acknowledge the role of ICES in assembling the group. Many of the ideas presented here have been developed within the project SPACE (Subpolar Atlantic Climate and Ecosystems), funded by the Nordic Council of Ministers. The authors also wish to acknowledge the helpful and constructive suggestions of G.H. Engelhard, M. Heino and G. Huse, who reviewed the initial version of the manuscript. This work was funded in part by the European Union Seventh Framework Programme project EUROBASIN (ENV.2010.2.2.1-1) under grant agreement number 264933. 
Anderson JT. 1988. A review of size dependent survival during pre-recruit stages of fishes in relation to recruitment. Journal of Northwest Atlantic Fisheries Science. 8:55-66.

Anker-Nilssen T, Lorentsen SH. 2004. Seabirds in the Norwegian Sea. In: Skjoldal HR, editor. The Norwegian Sea Ecosystem. Trondheim: Tapir Academic Press, p. 435-446.

Bailey RS. 1982. The population biology of blue whiting in the North Atlantic. Advances in Marine Biology. 19:257-355.

Bailey KM, Houde ED. 1989. Predation on eggs and larvae of marine fishes and the recruitment problem. Advances in Marine Biology. 25: 1-83.

Bainbridge V, Cooper G. 1973. The distribution and abundance of the larvae of the blue whiting, Micromestistius poutassou (Risso), in the north-east Atlantic, 1948-1970. Bulletins of Marine Ecology. 8:99-114.

Bartsch J, Coombs S. 1997. A numerical model of the dispersion of blue whiting larvae, Micromesistius poutassou (Risso), in the eastern North Atlantic. Fisheries Oceanography. 6:141-154.

Beaugrand G, Reid PC, Ibañez F, Lindley JA, Edwards M. 2002. Reorganization of North Atlantic Marine Copepod Biodiversity and Climate. Science. 296:1692-1694.

Brophy D, King PA. 2007. Larval otolith growth histories show evidence of stock structure in Northeast Atlantic blue whiting (Micromesistus poutassou). ICES Journal of Marine Science. 64:1136-1144.

Cabral HN, Murta AG. 2002. The diet of blue whiting, hake, horse mackerel and mackerel off Portugal. Journal of Applied Ichthyology. 18:14-23.

Dooley HD. 1984. Aspects of oceanographic variability on Scottish fishing grounds [PhD thesis]. Aberdeen, United Kingdom: University of Aberdeen. $154 \mathrm{p}$.

Edwards M, Beaugrand G, Reid PC, Rowden AA, Jones MB. 2002. Ocean climate anomalies and the ecology of the North Sea. Marine Ecology-Progress Series. 239:1-10.

Folkvord A, Hunter JR. 1986. Size-specific vulnerability of northern anchovy Engraulis mordax larvae to predation by fishes. Fishery Bulletin U.S. 84:859-869.

Fortier L, Quinonez-Velazquez C. 1998. Dependence of survival on growth in larval pollock Pollachius virens and haddock Melanogrammus aeglefinus: a field study based on individual hatch dates. Marine Ecology-Progress Series. 174: 1-12.

Fuiman L.A. 1994. The interplay of ontogeny and scaling in the interactions of fish larvae and their predators. Journal of Fish Biology. 45:55-79.

Fuiman LA, Gamble JC. 1989. Influence of experimental manipulations on predation of herring larvae by juvenile herring in large enclosures. Rapports et Procès-Verbaux des Réunions du Conseil International pour l'Exploration de la Mer. 191:359-365.

Hansen B, Østerhus S. 2000. North Atlantic-Nordic Seas exchanges. Progress in Oceanography. 45:109-208.

Häkkinen S, Rhines PB. 2004. Decline of subpolar North Atlantic circulation during the 1990s. Science. 304:555-559.

Hátún H, Payne MR, Jacobsen JA. 2009a. The North Atlantic subpolar gyre regulates the spawning distribution of blue whiting (Micromesistius poutassou). Canadian Journal of Fisheries and Aquatic Sciences. 66:759-770.

Hátún $H$, Payne MR, Beaugrand $G$, Reid PC, Sandø $A B$, Drange $H$, Hansen $B$, Jacobsen JA, Bloch D. 2009b. Large bio-geographical shifts in the north-eastern Atlantic Ocean: From the subpolar gyre, via plankton, to blue whiting and pilot whales. Progress in Oceanography. 80:149-162.

Hátún $H$, Sandø AB, Drange $H$, Hansen B, Valdimarsson H. 2005. Influence of the Atlantic subpolar gyre on the thermohaline circulation. Science. 309:1841-1844.

Heino M, Engelhard GH, Godø OR. 2008. Migration and hydrography determine the abundance fluctuations of blue whiting (Micromesistius poutassou) in the Barents Sea. Fisheries Oceanography 17:153-16. 
Hjort J. 1914. Fluctuations in the great fisheries of northern Europe viewed in the light of biological research. Rapports et Procès-Verbaux des Réunions du Conseil International pour l'Exploration de la Mer. 20: 1-228.

Holliday NP. 2003. Air-sea interaction and circulation changes in the northeast Atlantic. Journal of Geophysical Research. 108(C8). doi:10.1029/2002JC001344. PMID:14686320.

Holliday NP, Hughes SL, Beszczynska-Möller A. 2009. ICES report on ocean climate 2008. ICES Cooperative Research Report No. 298. 66 pages.

Houde ED. 2008. Emerging from Hjort's Shadow. Journal of Northwest Atlantic Fishery Science. 41: 53-70.

Hillgruber N, Kloppmann M, Westernhagen $\mathrm{H}$ von. 1995. Distribution of blue whiting Micromesistius poutassou larvae in the Porcupine Bank area, west of Ireland, in relation to hydrography and the feeding environment. ICES Document CM 1995/H:27.

Husebø A, Stenevik EK, Slotte A, Vikebø F, Fossum P, Folkvord A. 2009. Early hatching time in Norwegian spring spawning herring (Clupea harengus L.) results in increased survival. ICES Journal of Marine Science. 66:1710-1717.

ICES. 2009. Report of the Workshop on Blue Whiting Recruitment (WKBLUR), 10-12 November 2009, ICES Headquarters, Copenhagen. ICES Document CM 2009/RMC:09. 66 pages.

ICES. 2010a. Report of the Working Group on Widely Distributed Stocks (WGWIDE), 28 August - 3 September 2010, Vigo, Spain. ICES Document CM 2010/ACOM:15. 612 pages.

ICES. 2010b. Report of the Working Group on Northeast Atlantic Pelagic Ecosystem Surveys (WGNAPES). ICES Document CM 2010/SSGESST:20. 92 pages.

IPCC. 2007. Summary for Policymakers. In: Solomon S, Qin D, Manning M, Chen Z, Marquis M, Averyt KB, Tignor M, Miller HL, editors. Climate Change 2007: The Physical Science Basis. Contribution of Working Group I to the Fourth Assessment Report of the Intergovernmental Panel on Climate Change. Cambridge, United Kingdom: Cambridge University Press.

Lapolla A, Buckeley LJ. 2005. Hatch date distributions of young-of-year haddock Melanogrammus aeglefinus in the Gulf of Maine/Georges Bank region: implications for recruitment. Marine Ecology Progress Series. 290: 239-249.

Leggett WC, Frank KT. 2008. Paradigms in fisheries oceanography. Oceanography and. Marine Biology: An Annual Review. 46: 331-363.

Lohmann K, Drange H, Bentsen M. 2009. A possible mechanism for the strong weakening of the North Atlantic subpolar gyre in the mid-1990s. Geophysical Research Letters 36: L15602. doi:10.1029/2009GL039166.

Marshall CT, O'Brien L, Tomkiewicz J, Marteinsdóttir G, Morgan MJ, Saborido-Rey F, Köster FW, Blanchard JL, Secor DH, Kraus F, Wright P, Mukhina NV, Björnsson H. 2003. Developing alternative indices of reproductive potential for use in fisheries management: case studies for stocks spanning an information gradient. Journal of Northwest Atlantic Fishery Science. 33:161-190.

Marshall CT, Needle CL, Thorsen A, Kjesbu OS, Yaragina NA. 2006. Systematic bias in estimates of reproductive potential of an Atlantic cod (Gadus morhua) stock: implications for stock-recruit theory and management. Canadian Journal of Fisheries and Aquatic Sciences, 63:980-994.

Monstad T. 2004. Blue whiting. In: Skjoldal HR, editor. The Norwegian Sea Ecosystem. Trondheim: Tapir Academic Press p. 263-288.

Myers RA, Rosenberg AA, Mace PM, Barrowman N, Restrepo VR. 1994. In search of thresholds for recruitment overfishing. ICES Journal of Marine Science. 51:191-205.

Myers RA. 1998. When do environment recruitment correlations work? Reviews in Fish Biology and Fisheries. 8:285-305.

Nishimura A, Hamatsu T, Shida O, Mihara I, Mutoh T. 2007. Interannual variability in hatching period and early growth of juvenile walleye Pollock, Theragra chalcogramma, in the Pacific coastal area of Hokkaiso. Fisheries Oceanography. 16: 229-239. 
Olaso T, Gutierrez JL, Villamor B, Carrera P, Valdes L, Abaunza P. 2005. Seasonal changes in the north-eastern Atlantic mackerel diet (Scomber scombrus) in the north of Spain (ICES Division VIIIC). Journal of the Marine Biological Association of the United Kingdom. 85:415418.

Pepin P. 1991. The effect of temperature and size on development, mortality and survival rates of the pelagic early life stages of marine fishes. Canadian Journal of Fisheries and Aquatic Sciences. 48:503-518.

Pepin P, Spearre S Jr, Koslow JA. 1987. Predation on larval fish by Atlantic mackerel, Scomber scombrus, with comparison of predation by zooplankton. Canadian Journal of Fisheries and Aquatic Sciences. 44: 2012-18.

Planque B, Fromentin JM. 1996. Calanus and environment in the eastern North Atlantic.I. Spatial and temporal patterns of C. finmarchicus and C. helgolandicus. Marine EcologyProgress Series. 134:101-109.

Shepherd JG, Cushing DH. 1980. A mechanism for density dependent survival of larval fish as the basis of a stock-recruitment relationship. Journal du Conseil International pour l'Exploration de la Mer. 39:160-167.

Skjoldal HR, Dalpadado P, Dommasnes A. 2004. Food webs and trophic interactions. In: Skjoldal HR, editor. The Norwegian Sea Ecosystem. Trondheim: Tapir Academic Press p.447-506.

Skogen M, Monstad T, Svendsen E. 1999. A possible separation between a northern and a southern stock of the North Atlantic blue whiting. Fisheries Research. 41:119-131.

Slotte A, Johannessen A, Kjesbu OS. 2000. Effects of fish size on spawning time in Norwegian spring spawning herring (Clupea harengus L.). Journal of Fish Biology. 56:295310.

Svendsen E, Skogen MD, Monstad T. 1996. Modelling the Variability of the drift of blue whiting larvae and its possible importance for recruitment. ICES Document CM 1996/S:31. 23 pages.

Trippel EA. 1998. Egg size and viability and seasonal offspring production of young Atlantic cod. Transactions of the American Fisheries Society. 127:339-359.

Wade IP, Ellett DJ, Heywood KJ. 1997. The influence of intermediate waters on the stability of the eastern North Atlantic. Deep Sea Research Part I. 44:1405-1426.

Ware DM. 1975. Relation between egg size, growth and natural mortality of larval fish. Journal of the Fisheries Research Board of Canada. 32:2503-2512. 


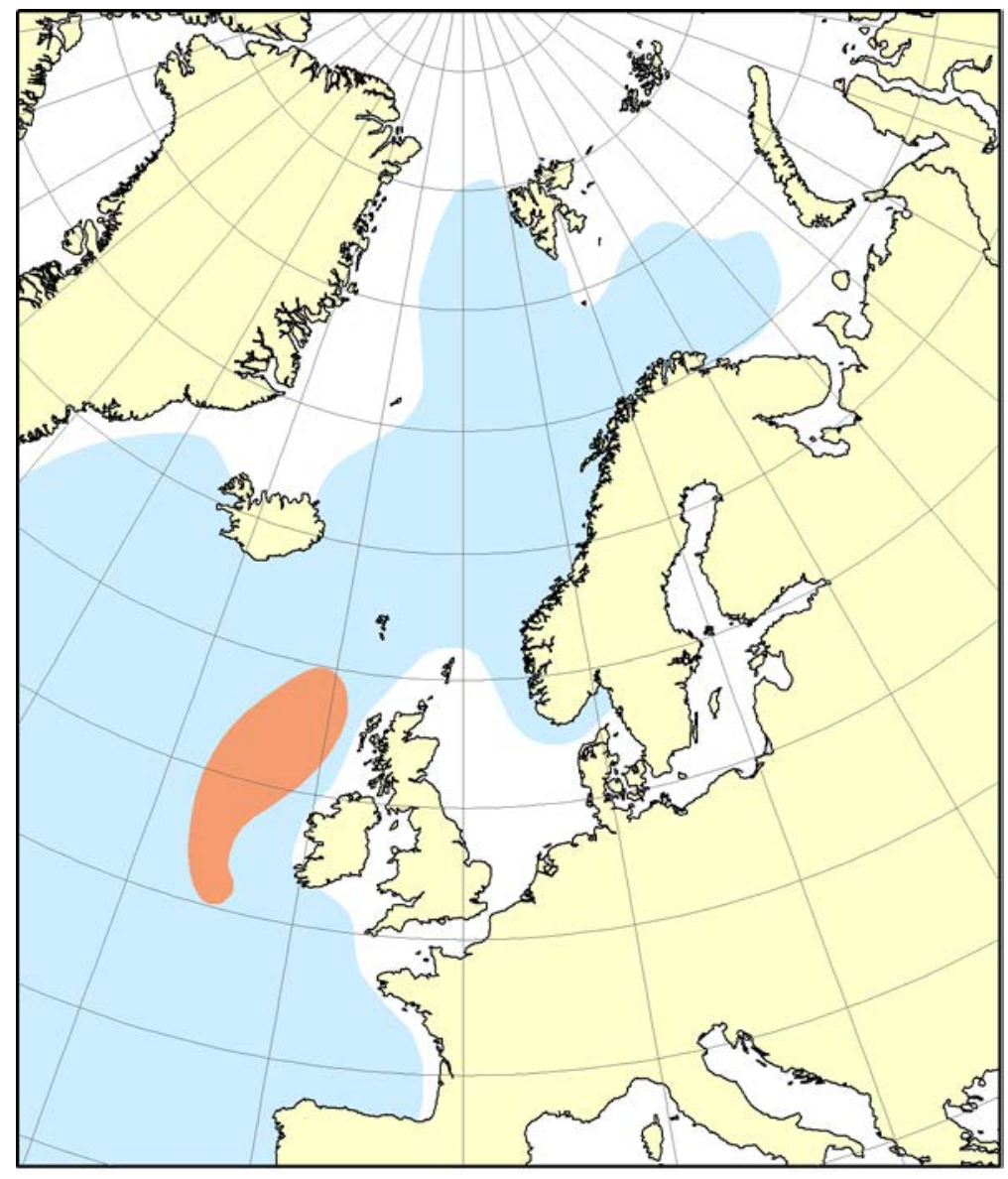

Main spawning area Distribution area

Figure 1. Spawning and distribution areas of blue whiting (after Bainbridge and Cooper, 1973; Baily, 1982; Monstad, 2004). 


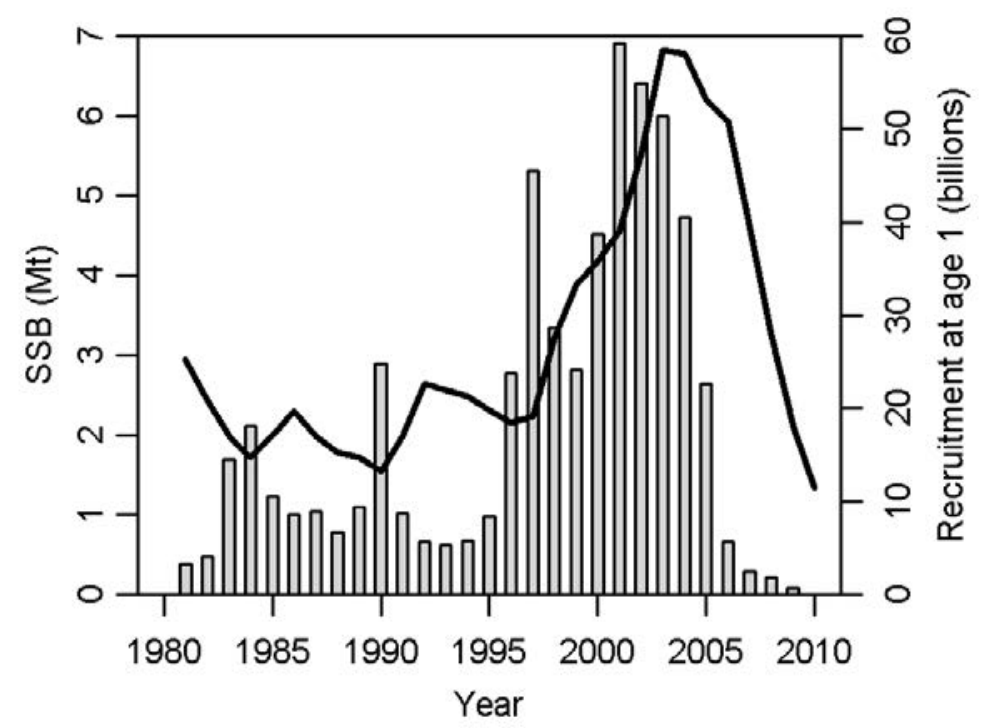

Figure 2. Development of the blue whiting stock from the analytical stock assessment (ICES, 2010a), showing the spawning stock biomass (heavy black line; left axis) and recruitment at age 1 (grey bars; right axis).

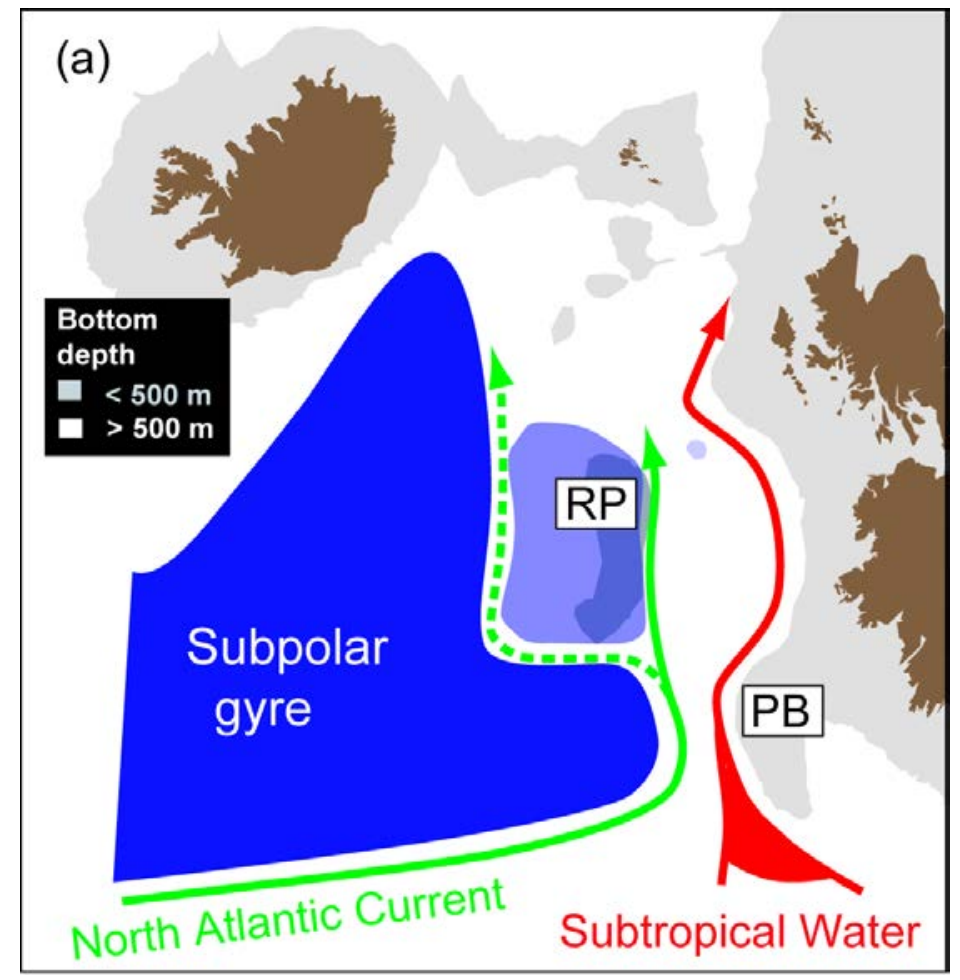

Figure 3. Simplified illustration of the source flows to the Rockall Region. a) A strong subpolar gyre results in strong influence of cold subarctic water near the Rockall Plateau (subarctic state). 


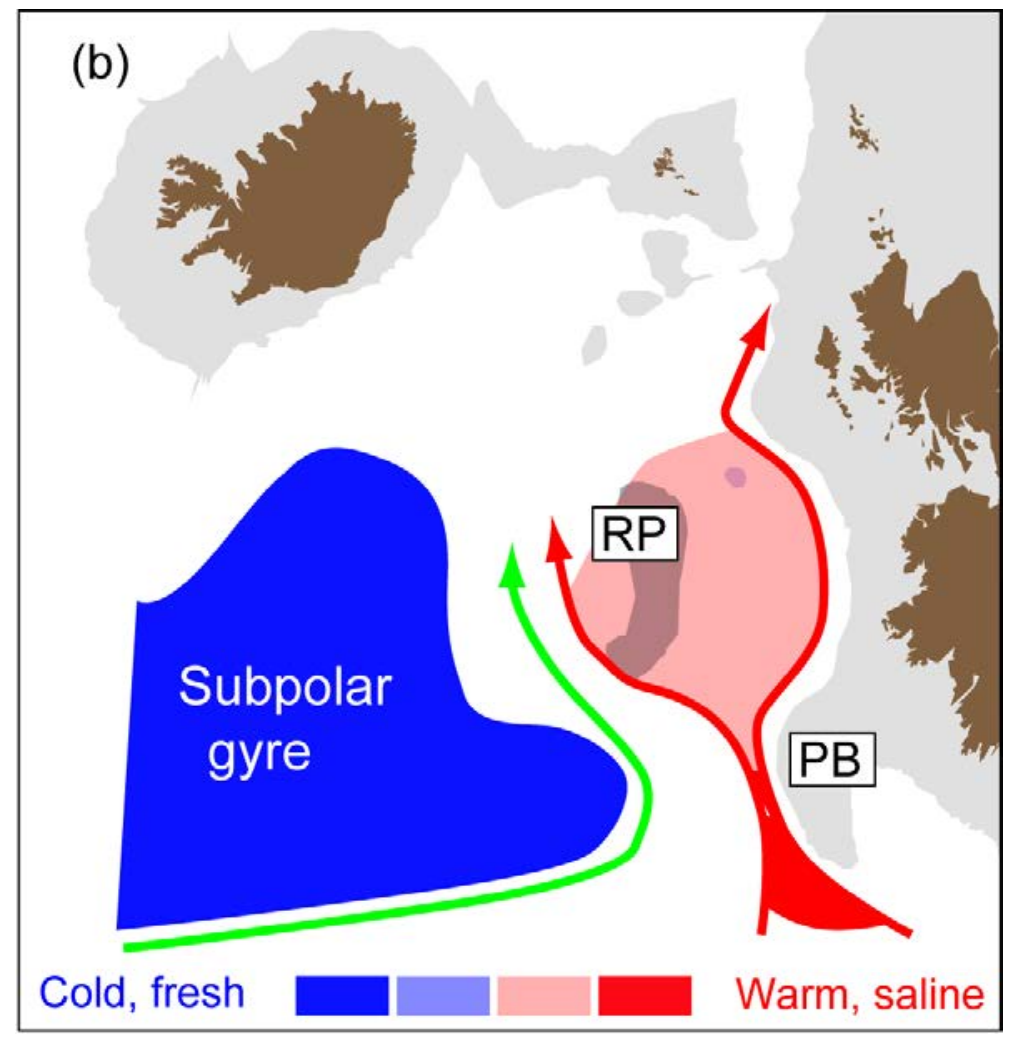

b) A weak gyre results in a warm subtropical anomaly near the plateau (From Hátún et al. 2009b) (subtropical state).

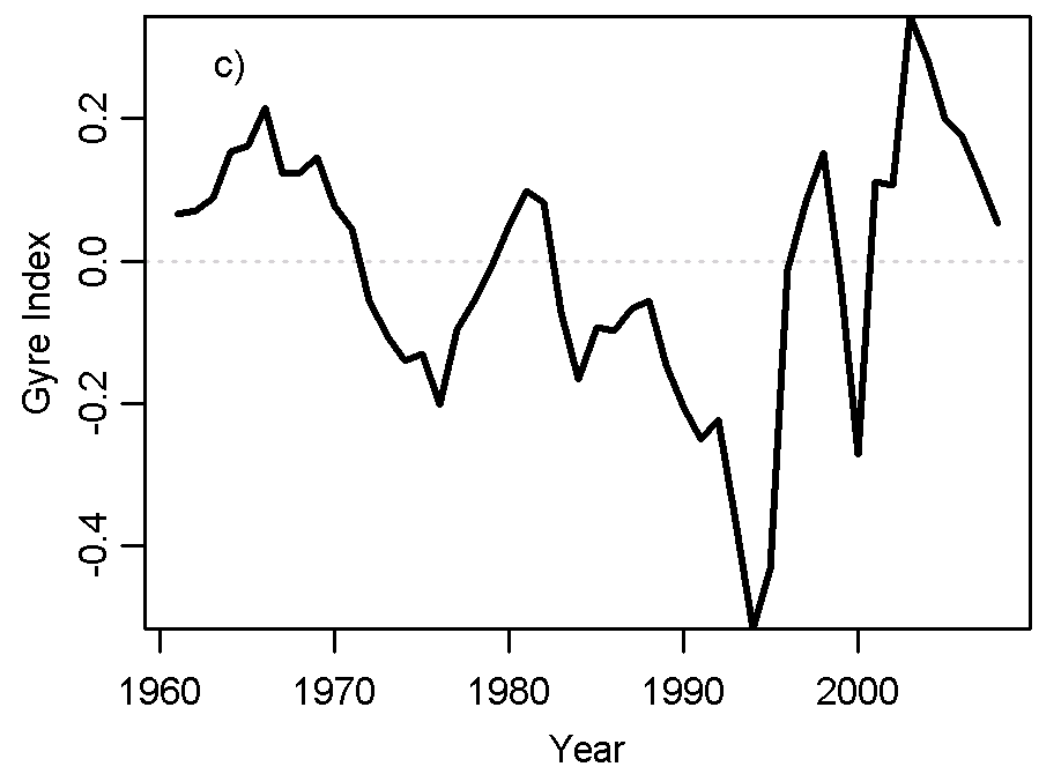

c) Time series of the sub-polar gyre index - a high value indicates a subtropical state, a low value a subarctic state. Abbreviations - RP: Rockall Plateau and PB: Porcupine Bank. (Hátún et al., 2005) 

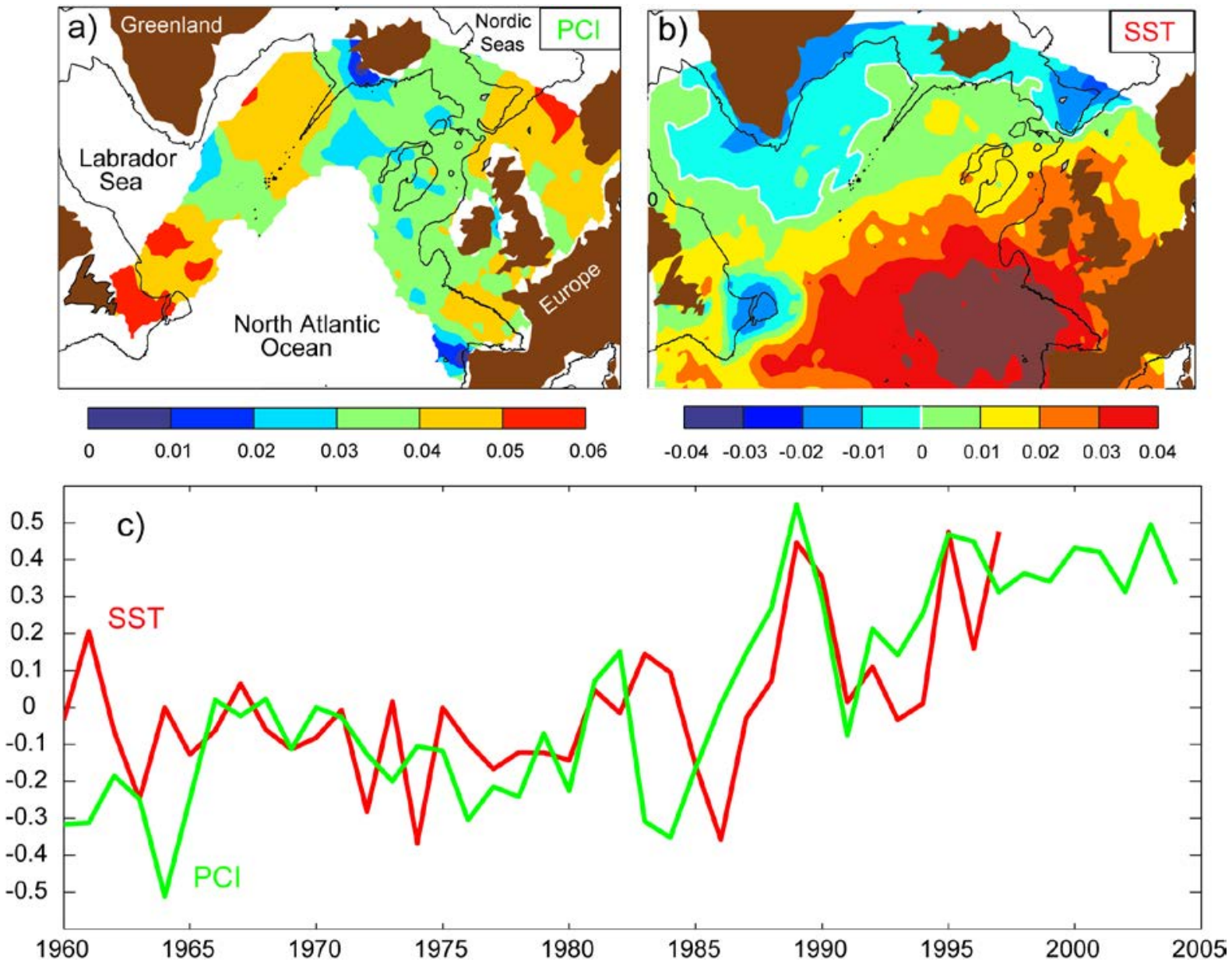

Figure 4. Variability modes related to Northern Hemisphere Temperature. Spatial patterns of (a) the first Phytoplankton Colour Index mode ( $\mathrm{PCl}$ ), and (b) the first SST mode. (c) The corresponding time series (principal components) (Hátún et al., 2009).

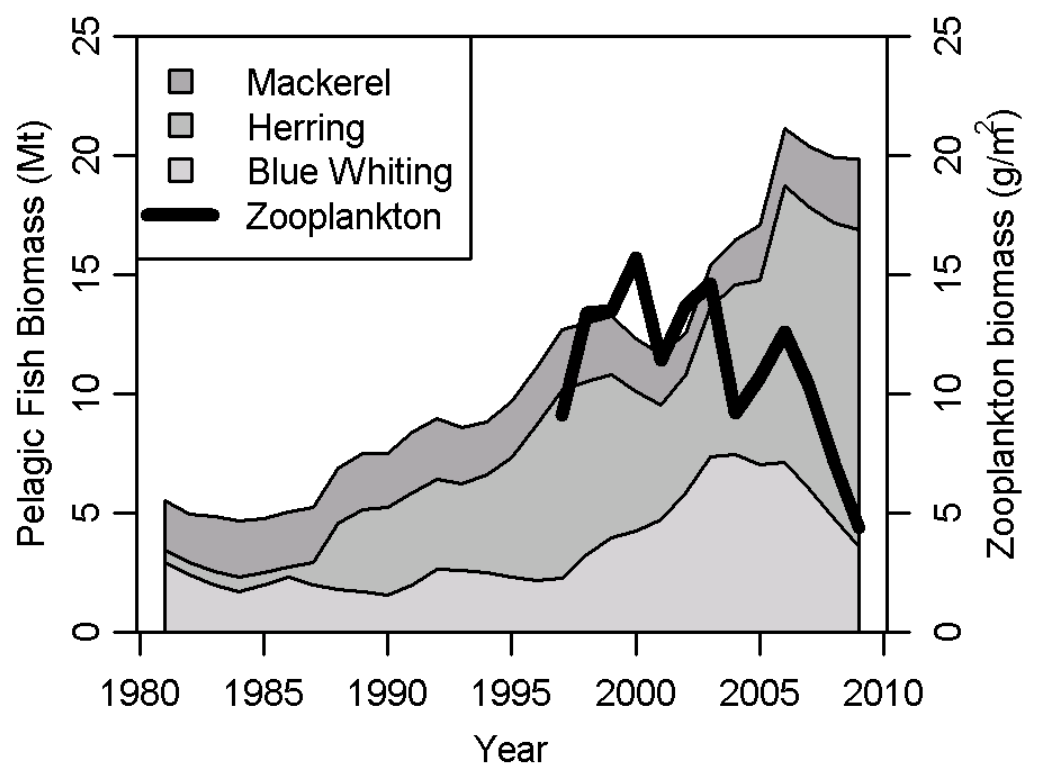

Figure 5. Fluctuations in total biomass of pelagic fish and zooplankton in the Norwegian Sea. Spawning stock biomass of mackerel (dark-grey area), Norwegian Spring-spawning herring 
(grey area) and blue whiting (left-grey area) from analytical stock assessment (ICES, 2010a). Average zooplankton density ( $\mathrm{g}$ dry weight. $\mathrm{m}^{-2}$; heavy black line) from the International ecosystem survey in the Nordic Seas (ICES, 2010b).
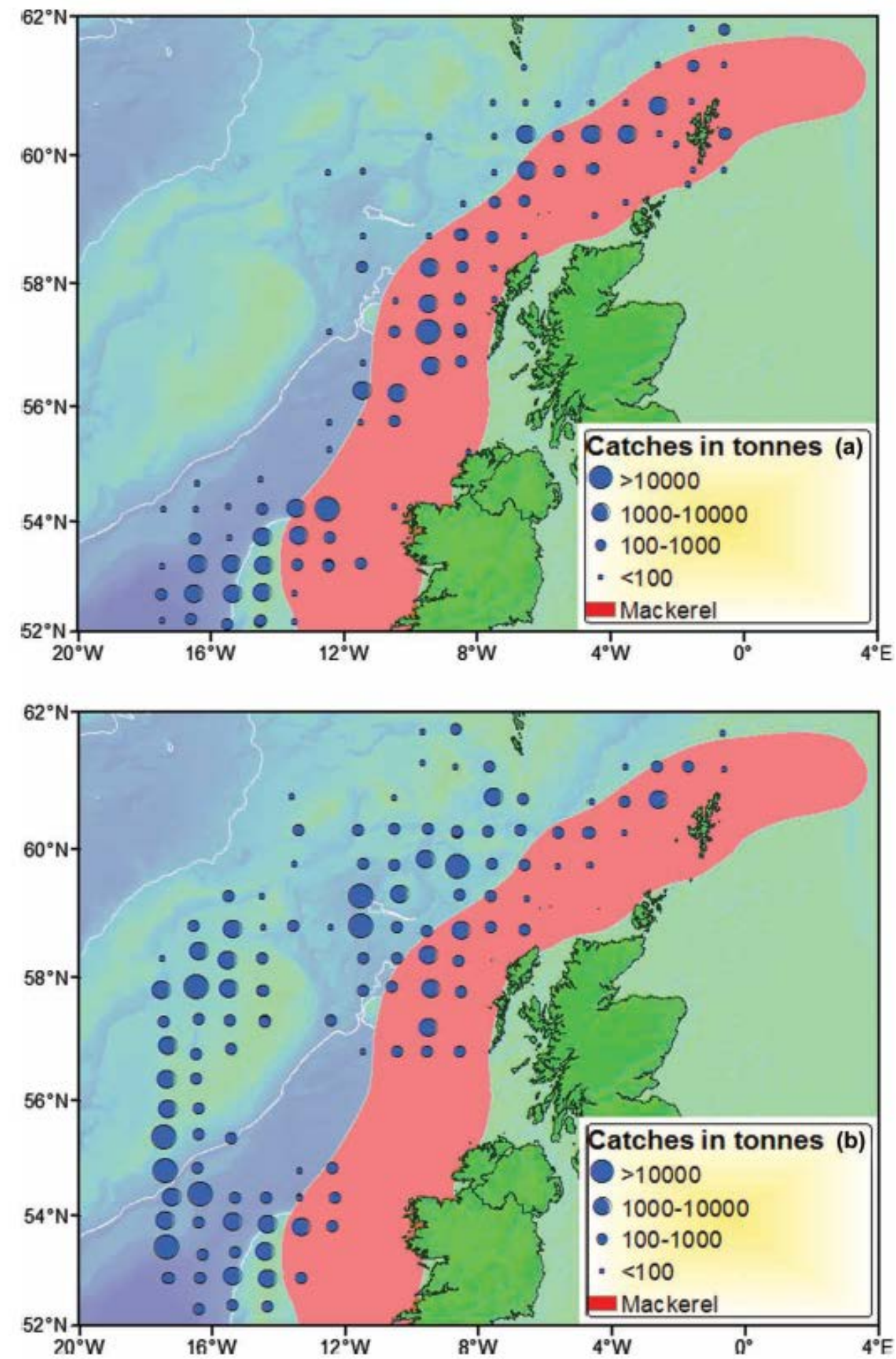

Figure 6. Maps showing mean catch of blue whiting by ICES squares in the pre-spawning period (quarter 1) during a) a period with low recruitment (1989-1996), and b) a period of high recruitment (1997-2005) (Hatun et al. 2009b), and the overlap with mackerel (based on catch distribution in 2005; ICES, 2010a). 

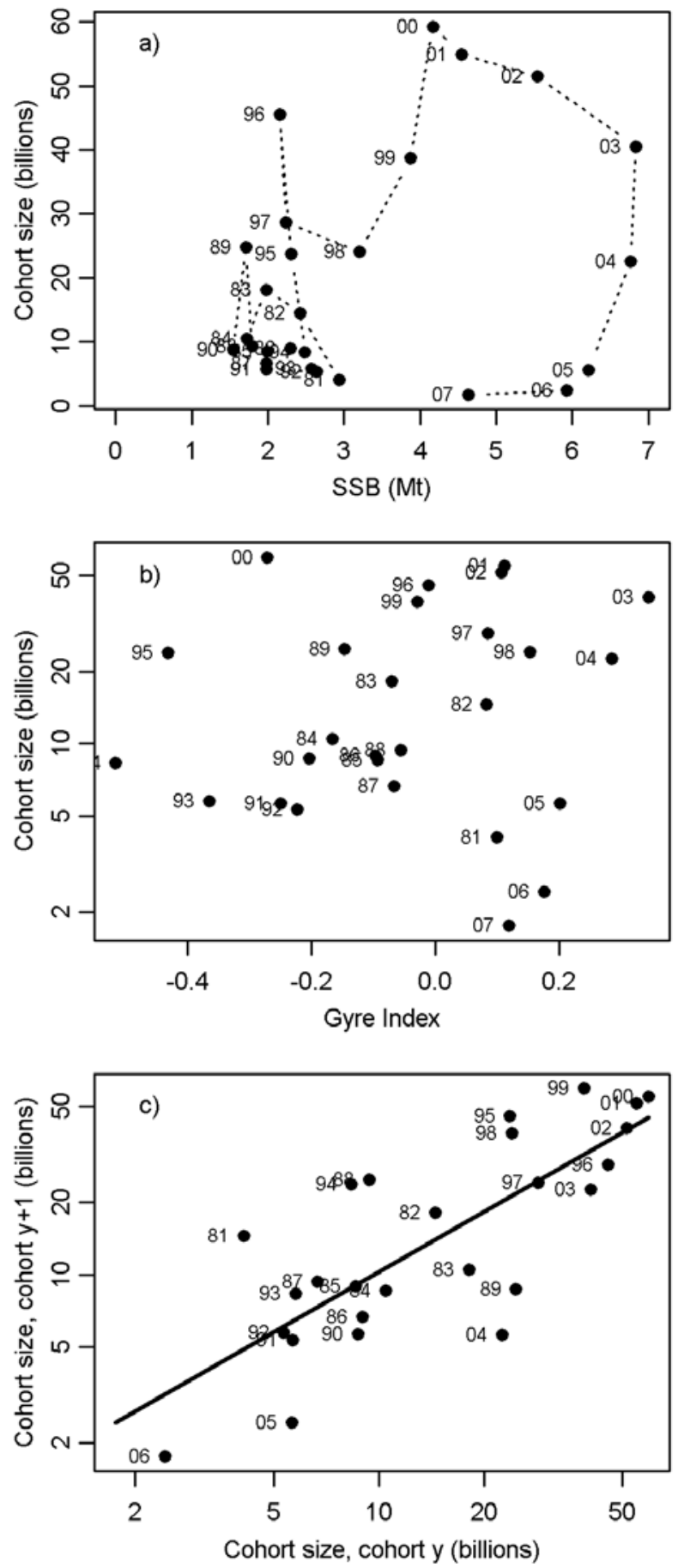

Figure 7. Potential recruitment prediction relationships a) Relationship between blue whiting spawning stock biomass (SSB) and the cohort size produced in a given year. Sequential years are joined by a line to enable visualisation of the SSB-recruitment trajectory. b) Relationship between the subpolar gyre index (ICES, 2009) and (log) cohort size of the corresponding year class c) Relationship between the (log) cohort size in a given year and in the subsequent year. Recruitment (cohort size) is estimated here at age 1 (ICES, 2010a). Due to a high uncertainty in the most recent recruitment estimate (2008 cohort) this value has been omitted from the analysis. Note that the cohort size is plotted on a logarithmic scale for figures $b$ and $c$. Points are labelled with the last two digits of the cohort. 


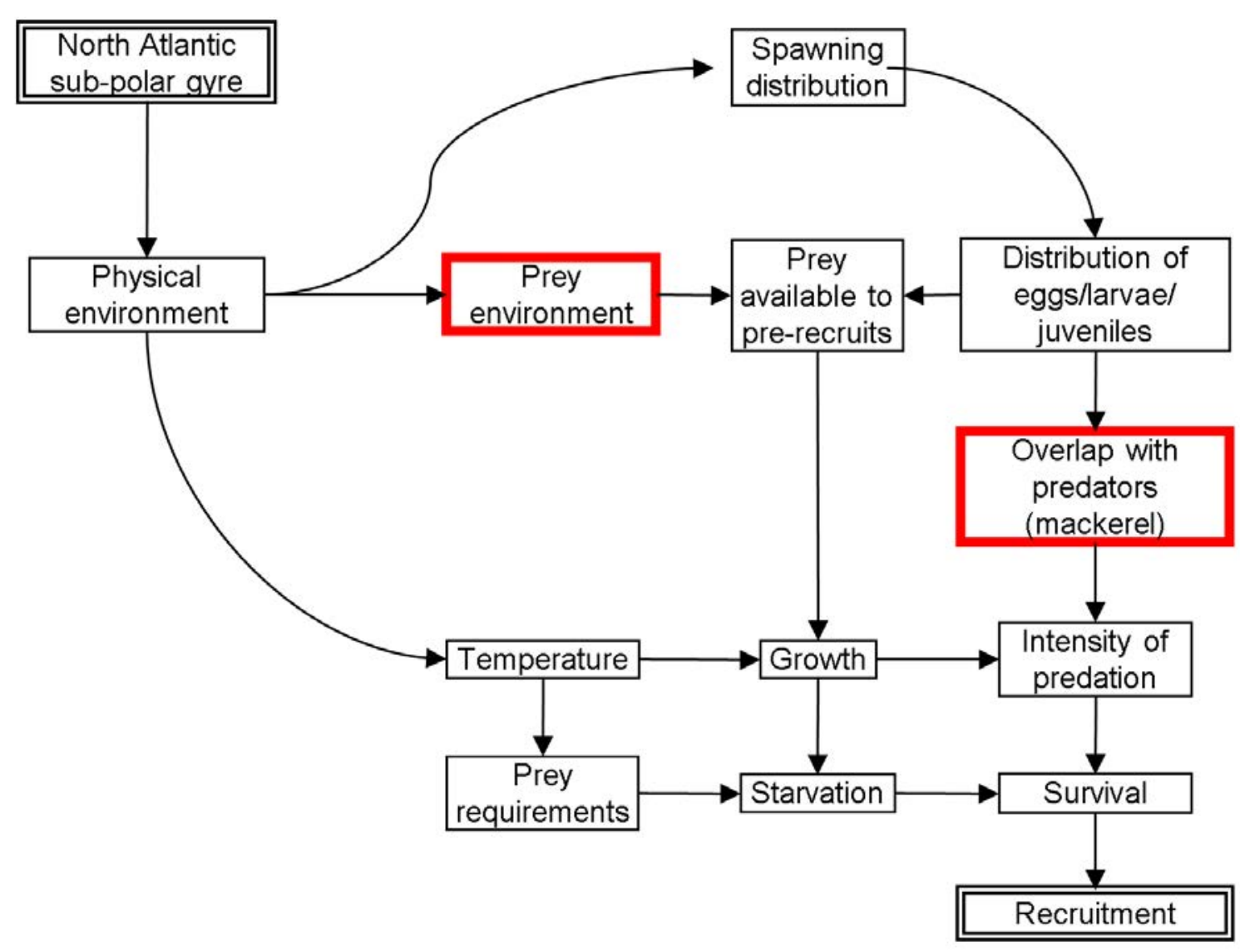

Figure 8. Summary of the proposed mechanisms potentially explaining recruitment of blue whiting. The two key hypotheses developed in this work are highlighted within the red boxes. Arrows indicate causal linkages between phenomena and should be read as "influences". 